\title{
A VIVÊNCIA DO DESEMPREGO: UM ESTUDO CRÍTICO DO SIGNIFICADO DO DESEMPREGO NO CAPITALISMO
}

\author{
THE EXPERIENCE OF BEING UNEMPLOYED: A CRITICAL STUDY \\ OF THE MEANING OFUNEMPLOYMENT IN CAPITALISM
}

Ligia Maria Soufen Tumolo 1

Paulo Sergio Tumolo 2

Resumo O artigo examina, primeiramente, os resultados de uma pesquisa com indivíduos que procuravam emprego por meio de encaminhamento do Sine - Sistema Nacional de Emprego - de Florianópolis (Santa Catarina), com o propósito de apreender as características mais marcantes de sua vivência como desempregados. Em seguida, ao analisar o significado do desemprego no interior da lógica societal capitalista, conclui que os desempregados se encontram numa situação de dificuldade e, no limite, na impossibilidade de vender não somente a força de trabalho, mas qualquer mercadoria, e, dessa forma, também na impossibilidade de comprar os meios de subsistência para poderem produzir suas vidas como seres humanos. Daí se pode entender que as características de suas vivências são expressão, no seu cotidiano, da produção de sua degradação como seres humanos e, ao mesmo tempo, de suas tentativas de reação a este processo.

Palavras-chave desemprego; capitalismo; vivência; mercado; produção social da vida
Abstract In a first stage, the article examines the results of a survey with individuals that were looking for a job by referral from the SINE Brazilian Employment System - in Florianópolis - Santa Catarina, in an attempt to find out the main characteristics of their experience as unemployed. Next, analysing the meaning of unemployment within the logic of capitalist society, it concludes that the unemployed have great difficulty in selling the force of his/her labour, and, in extreme cases, are totally unable, not just to sell this labour, but to sell any other merchandise, with the consequence that they have also great difficulty in buying — or are totally unable to buy - their means of subsistence so as to produce their lives as human beings. From this it is possible to presume that the characteristics of their experience are an expression, in their everyday life, of the production of their degradation as human beings as well as of their efforts to react against this process.

Key words unemployment, Capitalism, life-experience, market, social production of life. 
"A dor da gente não sai no jornal."

Chico Buarque

\section{O desemprego na contemporaneidade}

O desemprego tem sido um dos maiores problemas da sociedade contemporânea e, por esta razão, um dos temas mais debatidos e analisados. Em 1999, para uma população economicamente ativa mundial estimada em três bilhões de pessoas, havia cerca de um bilhão de trabalhadores vivendo com sua capacidade de trabalho subutilizada, o que significa dizer que, em cada três trabalhadores no mundo, um se encontrava na condição de desemprego ou de subemprego (Pochmann, 2001). Levantamentos estatísticos têm revelado, ainda, que nas últimas três décadas, o desemprego tem sido crescente, tanto nas economias centrais, quanto nas economias periféricas do capitalismo.

No Brasil, o desemprego vem crescendo de forma significativa, principalmente nos dois últimos decênios. Segundo Pochmann (2001), as transformações ocorridas na economia brasileira, a partir da segunda metade da década de 1980, têm gerado um desemprego sem precedentes na história do país, de tal maneira que vem atingindo o tecido social brasileiro como epidemia. Análise semelhante é feita por Mattoso (2000), ao afirmar que, atualmente, o desemprego apresenta uma amplitude nacional e caracteriza-se pela sua extraordinária intensidade. Além disso, seus índices não têm paralelo com outros momentos da história nacional.

Tal fenômeno é confirmado pelas duas agências brasileiras de pesquisa que são responsáveis pelo acompanhamento sistemático do desemprego de um lado, o Instituto Brasileiro de Geografia e Estatística ( IBGE), que realiza a Pesquisa Mensal de Emprego (PME), e, de outro, o Departamento Intersindical de Estatística e Estudos Sócio-econômicos (Dieese) e a Fundação Sistema Nacional de Análise de Dados (Seade), que, juntos, realizam a Pesquisa de Emprego e Desemprego (PED). A PME, realizada pelo IBGE, que acompanha o desemprego no mercado de trabalho em Recife, Salvador, Belo Horizonte, São Paulo, Rio de Janeiro e Porto Alegre, adota uma metodologia mais limitada de coleta e análise de dados sobre o desemprego, já que usa, como indicador principal, a taxa de desemprego aberto em sete dias. Para o IBGE, são considerados desempregados somente aqueles trabalhadores que estão sem qualquer trabalho e que tenham exercido algum ato de busca de emprego nos sete dias que antecederam a pesquisa. Esta perspectiva metodológica, mais restritiva na conceituação do desemprego, baseia-se apenas no desemprego aberto. Assim, os resultados produzidos pelo IBGE são taxas médias anuais de desemprego relativamente baixas ${ }^{3}$, se comparadas às taxas 
levantadas pela PED. Já a PED, realizada pelo Dieese/Seade, desenvolve sua pesquisa atualmente nos mercados metropolitanos de trabalho de São Paulo, Recife, Salvador, Belo Horizonte, Porto Alegre e Brasília. A metodologia de coleta e análise de dados adotada pelo Dieese/Seade nos parece mais apropriada para a compreensão do desemprego brasileiro, na medida em que permite englobar as variações das situações de emprego, características da sociedade brasileira atual. Para a PED, são considerados desempregados aqueles trabalhadores que estão na situação de desemprego aberto e desemprego oculto pelo trabalho precário e pelo desalento. Portanto, são considerados desempregados os trabalhadores que: a) não procuram trabalho ou exercem qualquer atividade na semana de referência da pesquisa, mas que tenham procurado emprego no decorrer do mês; b) exercem algum tipo de atividade irregular e descontínua simultaneamente à procura de trabalho, $\mathrm{o}$ chamado desempregado oculto pelo trabalho precário; e c) não procuraram trabalho no mês anterior, por se sentirem desestimulados pelo mercado de trabalho, mas procuraram trabalho nos últimos 12 meses, o que se denomina desemprego oculto pelo desalento. Essa metodologia resulta em taxas de desemprego anuais distintas e mais expressivas em relação à PME/IBGE. A despeito das diferenças observáveis nas taxas geradas a partir dessas pesquisas, ambas demonstram, de forma incontestável, o agravamento do crescimento do desemprego no Brasil conforme indicado na Tabela 1.

Tabela 1

Evolução das taxas de desemprego, índices percentuais para Brasil e São Paulo (1989-1999)

\begin{tabular}{lccccc}
\hline & 1989 & 1994 & 1998 & 1999 & $\begin{array}{c}\text { Variação em \% } \\
1989 / 1999\end{array}$ \\
\hline $\begin{array}{l}\text { São Paulo } \\
\begin{array}{l}\text { Desemprego total } \\
\text { Brasil }\end{array}\end{array}$ & 8,7 & 14,2 & 18,3 & $19,5^{*}$ & 110,3 \\
\begin{tabular}{l} 
Desemprego aberto \\
\hline
\end{tabular} & 3,4 & 5,1 & 7,6 & $7,8^{* *}$ & 123,5 \\
\hline
\end{tabular}

Fonte: Dados de São Paulo: Seade/Dieese, Pesquisas de Emprego e Desemprego (PED)

Dados do Brasil: IBGE, Pesquisa Mensal de Emprego (PME) (apud Mattoso, 2000 p. 13)

* Média obtida considerando-se os índices dos meses de janeiro a maio de 1999.

** Média obtida considerando-se os índices dos meses de janeiro a junho de 1999.

Como se pode verificar, as taxas produzidas pelos dois institutos são diferentes, devido a procedimentos distintos de levantamento de dados. Porém, o que mais chama a atenção é a evolução acentuada do desemprego no período referido, constatada pelas duas instituições: para o Seade-Dieese, $110,3 \%$; e para o IBGE, $123,5 \%$. 


\section{O desemprego e suas conseqüências na vida dos indivíduos}

Como o desemprego é um fenômeno que atinge os diversos países e segmentos sociais, pesquisadores de várias nacionalidades vêm conduzindo estudos com o objetivo de verificar as conseqüências do desemprego para a vida das pessoas, investigando principalmente as relacionadas à saúde e à saúde mental, como é o caso de Lejoyeux, Boulenguiez e Fichelle (2000), na Inglaterra. Outros pesquisadores têm tido uma perspectiva de análise sociológica das repercussões do desemprego, como se verifica em Cattani (1996), que examinou o caso francês. Outros, ainda, têm enfocado aspectos relacionados aos sentimentos e percepções relativos à situação do desemprego, como Brasileiro (2000) no Brasil4.

Esses estudos convergem no que se refere aos efeitos negativos do desemprego para os desempregados, seus familiares e a sociedade. Tais investigações demonstram que a situação de desemprego está associada à ocorrência de distúrbios psicológicos e à baixa auto-estima, assim como tem uma relação com a emergência e o agravamento de problemas sociais, como o aumento da criminalidade.

Com o intuito de dar continuidade a tais estudos e considerando o recrudescimento do desemprego na atualidade, sobretudo no Brasil, realizamos uma pesquisa qualitativa com 13 indivíduos que procuravam emprego por meio de encaminhamento do Sistema Nacional de Emprego (Sine) de Florianópolis (SC) ${ }^{5}$, com o propósito de buscar apreender as características mais marcantes da vivência desses indivíduos 6 . O conceito de vivência, neste estudo, se refere à configuração de sentidos que cada indivíduo vai desenvolvendo e atribuindo aos eventos que experimenta (nos quais se sente envolvido, na maioria das vezes, como protagonista ou vítima) no decorrer de sua vida, cotidianamente. Sentido se refere à possibilidade de atribuição de significado a eventos de que o indivíduo participa diretamente. Significados são compreendidos como representação simbólica das finalidades da ação, elaborada e assimilada por um sujeito social.

Do conjunto de entrevistados7, dez eram do sexo masculino e três do sexo feminino. A faixa etária variava entre 18 e 51 anos. O período de desemprego variava entre um mês e dois anos. Alguns dados que denotam o perfil desses indivíduos estão apresentados nas tabelas de 2 a 4. 
Tabela 2

\begin{tabular}{|c|c|c|c|c|c|c|c|c|c|c|c|c|}
\hline \multirow[t]{3}{*}{ Gênero } & \multicolumn{4}{|c|}{ Ensino Fundamental } & \multicolumn{4}{|c|}{ Ensino Médio } & \multirow{2}{*}{\multicolumn{2}{|c|}{$\begin{array}{l}\text { Ensino Superior } \\
\text { completo }\end{array}$}} & \multirow{2}{*}{\multicolumn{2}{|c|}{ Total }} \\
\hline & \multicolumn{2}{|c|}{ incompleto } & \multicolumn{2}{|c|}{ completo } & \multicolumn{2}{|c|}{ incompleto } & \multicolumn{2}{|c|}{ completo } & & & & \\
\hline & $\%$ & no. & $\%$ & no. & $\%$ & no. & $\%$ & no. & $\%$ & no. & $\%$ & no. \\
\hline Masculino & 15,3 & 2 & 7,6 & 1 & 15,3 & 2 & 30,7 & 4 & 7,6 & 1 & 76,9 & 10 \\
\hline Feminino & - & - & 7,6 & 1 & - & - & 15,4 & 2 & - & - & 23,1 & 3 \\
\hline Total & 15,3 & 2 & 15,3 & 2 & 15,3 & 2 & 46,1 & 6 & 7,6 & 1 & 100 & 13 \\
\hline
\end{tabular}

Fonte: Tumolo, L. M. S. (2002)

Tabela 3

Tempo de desemprego dos entrevistados segundo grau de escolaridade (Florianópolis — 2001)

\begin{tabular}{|c|c|c|c|c|c|c|c|c|c|c|c|c|}
\hline \multirow[t]{2}{*}{ Tempo (meses) } & \multicolumn{4}{|c|}{ Ensino Fundamental } & \multicolumn{4}{|c|}{ Ensino Médio } & \multirow{2}{*}{\multicolumn{2}{|c|}{$\begin{array}{l}\text { Ensino Superior } \\
\text { completo }\end{array}$}} & \multicolumn{2}{|c|}{ Total } \\
\hline & Incol & leto & com & eto & $\%$ & oleto & com & Teto & $\begin{array}{l}\text { con } \\
\%\end{array}$ & & 0 & no \\
\hline 1 a 2 meses & - & - & - & - & 7,7 & 1 & 15,4 & 2 & - & - & 23,1 & 3 \\
\hline 3 a 5 meses & 7,7 & 1 & 15,4 & 2 & 7,7 & 1 & - & - & 7,7 & 1 & 38,5 & 5 \\
\hline 6 a 8 meses & 7,7 & - & - & - & - & - & - & - & - & - & 7,7 & 1 \\
\hline 9 a 12 meses & - & - & - & - & - & - & 23,1 & 3 & - & - & 23,1 & 3 \\
\hline$>12$ meses & - & - & - & - & - & - & 7,7 & 1 & - & - & 7,7 & 1 \\
\hline Total & 15,4 & 2 & 15,4 & 2 & 15,4 & 2 & 46,2 & 6 & 7,7 & 1 & 100 & 13 \\
\hline
\end{tabular}

Fonte:Tumolo, L. M.S. (2002)

Tabela 4

Tempo de desemprego dos entrevistado segundo faixa etária (Florianópolis - 2001)

\begin{tabular}{lcccccccccccc}
\hline Faixa etária & & & \multicolumn{1}{c}{ Tempo de desemprego } \\
& 1 a 2 meses & 3 a 5 meses & 6 a 8 meses & 9 a 12 meses & $\begin{array}{c}12 \text { meses } \\
\text { ou mais }\end{array}$ & Total \\
& $\%$ & no. & $\%$ & no. & $\%$ & no. & $\%$ & no. & $\%$ & no. & $\%$ & no. \\
\hline 18 a 24 & 7,7 & 1 & 15,4 & 2 & - & - & - & - & - & - & 23,1 & 3 \\
25 a 29 & - & - & 7,7 & 1 & - & - & 7,7 & 1 & - & - & 15,4 & 2 \\
30 a 34 & 7,7 & 1 & 7,7 & 1 & 7,7 & 1 & 15,4 & 2 & - & - & 38,5 & 5 \\
35 a 39 & - & - & - & - & - & - & - & - & 7,7 & 1 & 7,7 & 1 \\
40 a 45 & 7,7 & 1 & - & - & - & - & - & - & - & - & 7,7 & 1 \\
45 ou mais & - & - & 7,7 & 1 & - & - & - & - & - & - & 7,7 & 1 \\
Total & 23,1 & 3 & 38,5 & 5 & 7,7 & 1 & 23,1 & 3 & 7,7 & 1 & 100 & 13 \\
\hline
\end{tabular}

Fonte:Tumolo, L. M.S. (2002)

O presente texto tem como finalidade, primeiramente, examinar, de forma resumida, os resultados da investigação desenvolvida sobre a vivência de desempregados na cidade de Florianópolis, e, em seguida, analisar o sig- 
nificado do desemprego no interior da lógica societal capitalista para, desta forma, buscar compreender as origens e fundamentos sociais dessa vivência.

\section{A vivência dos desempregados}

Sistematizamos as características da vivência dos desempregados entrevistados a partir da análise dos relatos dos participantes desta pesquisa, nos seguintes critérios: a) A busca incessante pelo emprego é uma ocupação?; b) O desemprego interfere no dia e na noite do desempregado; c) A responsabilidade pelo desemprego; d) A possibilidade da transgressão às normas sociais a partir da impossibilidade de satisfação de necessidades básicas; e) A família: de provedora à necessidade de ser provida; f) Queda no padrão de consumo; g) Não me falta nada, só decidir sobre minha própria vida; h) Distanciamento social; i) Desemprego: falta da atividade ou do salário? j) Os sentimentos diante da situação do desemprego; k) A desconsideração pelo desempregado; l) Precisamos ter esperança!; m) O desemprego dificulta o planejamento da vida futura.

Apresentam-se, a seguir, resumidamente, os resultados da pesquisa.

A situação do desemprego não significa que os desempregados tenham tempo livre para outras atividades desvinculadas de sua inserção no mercado de trabalho. Eles precisam desenvolver várias tarefas e utilizar o tempo de que dispõem para procurar oportunidades de inserção no mercado de trabalho.

A condição de desemprego interfere na vida do desempregado como um todo, ou seja, mesmo nos momentos em que o desempregado não está desenvolvendo as tarefas específicas de busca pelo emprego, está envolvido com a situação de desemprego. As preocupações com o desemprego geram interferências nas outras atividades do desempregado, já que afetam a forma como os desempregados se relacionam com outras pessoas, como também prejudicam as horas destinadas ao descanso.

Os desempregados entrevistados se responsabilizam pela sua situação de desemprego, ou seja, atribuem à sua baixa escolaridade, à sua insuficiente qualificação profissional, à sua pouca experiência profissional, à sua idade ou raça, os motivos de seu desemprego. Eles parecem desconhecer o aumento das taxas de desemprego na sociedade brasileira contemporânea.

Os participantes da pesquisa enfatizam que seus valores impediriam a efetivação de atos ilícitos, mas revelam que não condenam aqueles que os cometem, devido a uma situação extrema de impossibilidade em adquirir as mercadorias essenciais para garantir a sobrevivência deles e de suas famílias.

A família tem um forte significado para o trabalhador desempregado. Normalmente, a família de origem atua dando apoio, principalmente finan- 
ceiro. Há casos, no entanto, em que o desempregado não pode contar com a família de origem, ficando desamparado financeiramente. Os cônjuges, geralmente, são descritos como pessoas que fornecem suporte afetivo e material, já que incentivam a busca pelo emprego e assumem as despesas da família. Porém, de forma geral, verifica-se uma perda na qualidade da relação entre o casal, devido às preocupações geradas pelo desemprego. A consciência da responsabilidade em prover os bens necessários para os filhos e a preocupação em não conseguir cumpri-la são enfatizadas pelos participantes que têm filhos dependentes.

A queda no padrão de consumo é um fator central decorrente da situação do desemprego. Os participantes demonstram não conseguir renovar os bens que costumavam comprar, e passam a vender algumas mercadorias adquiridas com o objetivo de obter recursos financeiros para comprarem outras mais necessárias. Em casos extremos, contraem dívidas, sem terem a possibilidade de quitá-las.

Os entrevistados relatam a perda no poder de decisão sobre a condução das próprias vidas, já que a situação de desemprego gera uma dependência de outras pessoas, que são os provedores de suas necessidades básicas. De maneira geral, essa situação de dependência tem uma conotação de submissão, já que os participantes desempregados sentem que têm de se sujeitar às regras e decisões daqueles que os sustentam.

Ao serem questionados sobre qual a dimensão mais importante do trabalho, se a atividade ou o salário, todos os participantes atribuem uma importância fundamental ao trabalho como meio principal de obtenção de uma remuneração que os permite comprar mercadorias necessárias. A equivalência de importância entre a atividade e a remuneração foi apontada por dois dos participantes, que demonstram não dissociar a atividade da remuneração, sendo que a segunda não tem sentido sem o exercício da primeira.

O distanciamento social, expresso na diminuição da freqüência em encontros sociais, gerado pela necessidade de redução nos gastos, também faz parte da vivência do desempregado, no momento da situação de desemprego.

De outra parte, é possível inferir, considerando os limites do número de entrevistados, que o desemprego atinge pessoas de todos os níveis de escolaridade, e que mesmo aquelas que possuem um grau mais elevado de escolarização, como é o caso da maioria dos entrevistados, têm encontrado dificuldade em conseguir emprego (Tabela 3).

A falta de informações sobre os critérios de seleção para as funções às quais concorrem, como também a ausência de uma resposta sobre os resultados dos processos seletivos aos quais se submetem, gera, nos desempregados, uma sensação de serem desconsiderados pelas organizações de trabalho.

Diante de tantas tentativas frustradas de reingresso no mercado de trabalho, e da conseqüente perda da esperança, assim como do desespero cau- 
sado pela situação do desemprego, os entrevistados adotaram algumas expressões e atitudes para recuperar a esperança e aliviar as tensões. A crença no pensamento positivo e religioso, assim como a prática de longas caminhadas, funcionam como estratégias para minimizar os impactos do desemprego e possibilitam a continuidade no processo de busca de reinserção no mercado de trabalho.

O planejamento da vida futura também fica dificultado devido à situação do desemprego, já que a ausência de recursos financeiros compromete o investimento no desenvolvimento profissional e na aquisição de bens materiais.

De forma geral, os sentimentos gerados pela situação do desemprego têm uma conotação desagradável, associados a uma experiência de sofrimento por parte dos desempregados. O desespero, a perda da esperança, o desamparo, a tristeza, a revolta e a desorientação são sentimentos verbalizados e expressos de forma contundente pelos participantes. Nenhum sentimento descrito com uma conotação agradável foi associado, pelos participantes, à experiência do desemprego.

Parece fundamental destacar que entre os 13 participantes da pesquisa, dez choraram de forma dramática ao relatarem suas experiências diante da situação do desemprego. Esse fato demonstra que a vivência do desemprego se caracteriza como uma experiência de grande sofrimento para os desempregados, e que denota o processo de sua degradação como seres humanos, já que ficam limitados somente à aquisição das mercadorias necessárias para continuarem sobrevivendo.

Vários elementos que compõem os resultados desta pesquisa são coincidentes e outros são distintos e/ou complementares em relação àquelas realizadas por outros estudiosos ${ }^{9}$ que examinaram o fenômeno. Todas as pesquisas evidenciam que a situação de desemprego é sentida, de forma geral, como uma situação geradora de grande sofrimento, configurando-se como uma experiência bastante negativa para aqueles que a vivenciam.

Contudo, para que se possa compreender o desemprego e sua determinação na vida humana, é necessário entendê-lo para além dele mesmo, ou seja, é preciso buscar compreendê-lo como um fenômeno que se produz no interior de determinadas relações sociais, as relações capitalistas 10 .

\section{O significado do desemprego na lógica do capitalismo11}

No capitalismo, a produção da vida humana se processa por intermédio do mercado, que pode ser entendido, grosso modo, como o lugar social no qual todos os indivíduos, para poderem viver, precisam comprar e vender mercadorias. 
Nessa sociedade, os indivíduos têm de ir ao mercado para comprar as mercadorias necessárias para sua satisfação — os meios de subsistência realizando assim sua condição de compradores/consumidores. Contudo, ninguém pode comprar se "antes" não vender, quer dizer, para poderem comprar os meios de subsistência, os indivíduos precisam vender alguma mercadoria, qualquer que seja, efetivando, dessa forma, sua condição de produtores/vendedores. Isso significa que, para produzirem sua vida na sociedade do capital, todos os indivíduos, salvo algumas exceções, são produtores e ao mesmo tempo consumidores, ou seja, vendedores e compradores de mercadorias.

$\mathrm{Na}$ forma social capitalista, portanto, somente mediante a venda de alguma mercadoria, quer dizer, algum produto qualquer ou a força de trabalho em especial, é possível adquirir os meios de subsistência necessários para a manutenção da vida humana. Os que detêm os meios de produção são também proprietários dos bens que são produzidos e, dessa forma, podem vendê-los para comprar as mercadorias necessárias para sua sobrevivência. Todavia, outros indivíduos, que não dispõem dos meios de produção necessários para produzir algum bem, são obrigados a vender sua força de trabalho para, então, obterem alguma remuneração e realizarem a troca pelos produtos necessários para produzirem suas vidas, os meios de subsistência. Isso significa que, no capitalismo, existem, grosso modo, dois segmentos sociais que se constituem e se diferenciam como vendedores: de um lado, os proprietários dos meios de produção que, por decorrência, são também proprietários das mercadorias produzidas e, por esta razão, vendedores destas mesmas mercadorias, e, de outro, os que estão privados dos meios de produção e, dessa forma, tendo como única propriedade sua força de trabalho, são vendedores desta mercadoria.

\section{Proprietários de meios de produção e vendedores de mercadorias}

Abordaremos, inicialmente, os primeiros vendedores, ou seja, aqueles que não vendem a força de trabalho, mas outras mercadorias, já que são proprietários de meios de produção.

Pode-se dizer, em linhas gerais, que, no capitalismo, existem duas relações sociais de produção de mercadorias que, embora articuladas, são distintas e originam duas formas de mercado: as relações de produção especificamente capitalistas e as relações de produção não-capitalistas. As primeiras, que expressam o mercado especificamente capitalista, se caracterizam pela compra da força de trabalho do trabalhador pelo capitalista, detentor dos meios de produção, de tal maneira que a força de trabalho produz uma mercadoria que é propriedade do capitalista, e este a vende no mercado pe- 
lo seu valor. Ao produzir a mercadoria que vai ser vendida, o trabalhador produz também mais-valia, que será acumulada pelo capitalista, em um movimento incessante, configurando o movimento do capital. Tal relação só ocorre quando existem dois sujeitos sociais, que estabelecem a compra e venda da força de trabalho. De um lado, estão os proprietários dos meios de produção e, de outro, os trabalhadores que vendem sua força de trabalho, de tal maneira que os trabalhadores produzem mercadoria para o capitalista, que vai vendê-la, realizando, assim, a extração da mais-valia, em um processo insaciável de valorização de valor.

A produção de mercadorias pode ocorrer também em relações sociais não especificamente capitalistas, que configuram outra forma de mercado, e que se caracterizam pela inexistência da compra e venda da força de trabalho. Ou seja, os proprietários dos meios de produção se utilizam da própria força de trabalho, com a qual produzem mercadorias e as vendem no mercado. Por essa razão, em tais relações ocorre apenas a produção de mercadoria, de valor, mas não de mais-valia, não havendo possibilidade de produção e reprodução do capital. Um exemplo é a produção individual, familiar ou cooperativa de qualquer mercadoria, seja agrícola, industrial ou de serviço. Um camponês, proprietário de meios de produção, que, junto com sua família, produz feijão para vender, ou uma cooperativa, de propriedade coletiva, que fabrica roupas para levar ao mercado, ou ainda um indivíduo que produz a mercadoria serviço de assistência técnica de computadores, são alguns exemplos concretos de relações sociais de produção que não são capitalistas, uma vez que nelas se produz apenas mercadoria, valor, mas não se produz mais-valia e, por conseguinte, capital.

Não obstante, tais relações sociais, responsáveis pela produção da vida de parte da humanidade, tendem a se restringir, na medida em que as relações de produção especificamente capitalistas tendem a se ampliar, relativamente, comprimindo o mercado não-capitalista. Os produtores e vendedores de mercadorias produzidas por meio de relações de produção não-capitalistas concorrem com empresas que se encontram na lógica da produção capitalista, que é muito mais propícia ao desenvolvimento da força produtiva do trabalho, sobretudo pela combinação de alterações nas formas de organização e gestão do trabalho com incorporação de inovações tecnológicas, e que resulta numa diminuição do valor de suas mercadorias. Esta redução deixa aqueles produtores concorrentes sem ou com poucas chances de competir e de sobreviver no mercado, já que sua produção não consegue acompanhar o grau de desenvolvimento da força produtiva do trabalho e, muitas vezes, se caracteriza por ser artesanal ou semi-artesanal. Convém assinalar que o valor de uma mercadoria corresponde a um quantum socialmente necessário de trabalho (abstrato) para produzi-la, e não ao quantum de trabalho efetivamente presente nela. 
Isso implica que as empresas que conseguem aumentar sua produtividade, por meio do aumento da força produtiva do trabalho, logram diminuir o valor da mercadoria, abrindo uma vantagem sobre seus concorrentes. Estes, por sua vez, se encontram no seguinte dilema: ou aumentam a força produtiva do trabalho em suas empresas no mesmo ou em maior grau que o primeiro, ou são por ele eliminados. O processo, todavia, se reinicia ad infinitum.

Esse movimento incessante resulta numa tendência de queda generalizada do valor das mercadorias, cujo efeito prático é a eliminação dos produtores de mercadorias que não conseguem incorporar, no ritmo exigido, os elementos concernentes à elevação da força produtiva do trabalho, e expressa, portanto, a "guerra de vida e morte" que os produtores e vendedores de mercadorias estabelecem no cotidiano do mercado 12 .

Dessa forma, a ação das empresas capitalistas tende a eliminar ou restringir o campo de atuação dos concorrentes que não estabelecem a relação especificamente capitalista. Ocorre, assim, uma ampliação do mercado especificamente capitalista e, ao mesmo tempo, uma diminuição da possibilidade de produção de mercadorias fora do espaço produtivo capitalista. Apesar da possibilidade da abertura de um negócio próprio, a propensão é que os indivíduos encontrem cada vez mais dificuldade de produzir e vender mercadoria para poderem produzir sua vida.

Embora o espaço de sobrevivência fora do mercado capitalista tenda a ser cada vez menor, isso não significa dizer que não existam, ou deixarão de existir, trabalhadores individuais ou cooperativados que produzam suas mercadorias e concorram com as grandes empresas, mas este espaço inclinase a ser cada vez menor. Portanto, embora os indivíduos tenham possibilidade de vender alguma mercadoria que não a força de trabalho13, há uma diminuição relativa dessa possibilidade, na medida em que há um aumento relativo do espaço de atuação da relação de produção especificamente capitalista.

\section{Vendedores de força de trabalho}

No capitalismo, os seres humanos privados da propriedade de meios de produção são obrigados a vender a única mercadoria de que dispõem, sua força de trabalho14, para, dessa forma, poderem comprar os meios de subsistência. Por isso, o valor da força de trabalho corresponde ao valor dos meios de subsistência que devem satisfazer as necessidades humanas da família do trabalhador, de acordo com o grau de desenvolvimento da sociedade na qual está inserida.

Contudo, embora o mercado especificamente capitalista de produção de mercadorias aumente, conforme assinalado anteriormente, ocorre em seu 
âmbito uma redução relativa do mercado de trabalho. Esse movimento acontece de forma concomitante e articulada, ou seja, o 'mercado capitalista' se amplia reduzindo o 'mercado de trabalho capitalista'. O capital requer, em termos relativos, cada vez menos força de trabalho na produção de mercadorias na relação especificamente capitalista. Há uma redução relativa, portanto, do mercado da força de trabalho, ocasionando um incremento do contingente de trabalhadores supérfluos, que tem sido denominado por alguns autores, como Antunes (1999), de desemprego estrutural. Isto se deve à própria lógica do capital, expressa, sinteticamente, no aumento da composição orgânica do capital, fruto da concorrência intercapitalista e de sua decorrente necessidade de diminuição do valor das mercadorias mediante o aumento de produtividade, conforme já analisado anteriormente. O efeito desse processo é a constante dispensa relativa da força de trabalho15, ou seja, para o capital a força de trabalho se torna cada vez mais dispensável.

A respeito dessa questão, e discorrendo sobre o capitalismo contemporâneo, por meio da caracterização do modelo toyotista, Antunes (1999) afirma que o objetivo, neste padrão, é garantir a flexibilização do aparato produtivo, da organização do trabalho e também dos trabalhadores, que são absorvidos e descartados facilmente e sem custos, de acordo com as necessidades impostas para a acumulação do capital. Ao se referir às conseqüências da lógica adotada pelo capital para os trabalhadores, o autor assinala que

“a força humana de trabalho é descartada com a mesma tranqüilidade com que se descarta uma seringa. Assim faz o capital, e há então uma massa enorme de trabalhadores e trabalhadoras que já são parte do desemprego estrutural, são parte do monumental exército industrial de reserva que se expande em toda parte. Essa tendência tem se acentuado, em função da vigência do caráter destrutivo da lógica do capital, muito mais visível nesses 20, 30 anos" (Antunes, 1999, p. 200).

Antunes ainda faz algumas considerações a respeito do direito ao trabalho para a produção da vida dos trabalhadores, assim como expressa sua opinião sobre a situação dramática em que os trabalhadores desempregados estão submetidos, principalmente aqueles que se situam na América Latina, na medida em que não dispõem de qualquer seguridade social, e faz a seguinte reflexão:

“o direito ao trabalho é uma reivindicação necessária não porque se preze e se cultue o trabalho assalariado, heterodeterminado, estranhado e fetichizado (que deve ser radicalmente eliminado com o fim do capital), mas porque estar fora do trabalho, no universo do capitalismo vigente, particularmente para a massa de trabalhadores e trabalhadoras (que totalizam mais de dois terços da humanidade) que vivem no chamado Terceiro Mundo, desprovidos completamente de instrumentos 
de seguridade social, significa uma desefetivação, des-realização e brutalização ainda maiores do que aquelas já vivenciadas pela classe-que-vive-do-trabalho" (Antunes, 1999, p. 177-8, grifos do autor) ${ }^{16}$.

\section{Considerações finais}

Articulando-se as situações dos vendedores de mercadorias apresentadas, constata-se um aumento na dificuldade para que os indivíduos vendam sua força de trabalho para o mercado especificamente capitalista, tendo como conseqüência o aumento das taxas médias de desemprego, assim como uma tendencial diminuição da possibilidade de produção social da vida fora do mercado capitalista. Em ambos os mercados, tende a aumentar a dificuldade em vender alguma mercadoria, seja ela força de trabalho ou outra mercadoria qualquer, o que resulta em uma dificuldade cada vez maior de sobreviver, na medida em que aumenta a dificuldade para que os indivíduos possam comprar as mercadorias necessárias para produzirem sua própria vida.

A partir dessa análise do movimento do capital, é possível compreender que os trabalhadores são, relativamente, menos necessários nas empresas capitalistas e, portanto, têm mais dificuldade de vender sua força de trabalho, assim como menos possibilidade de obterem sucesso ao montar um negócio próprio - individual ou na forma de cooperativa —, na medida em que se torna cada vez mais difícil concorrer com a produção de mercadorias na forma capitalista. A combinação desses fenômenos implica que, na forma social capitalista, os trabalhadores estão se produzindo cada vez mais degradados como seres humanos, uma vez que têm cada vez mais dificuldades de comprar seus meios de subsistência, porque têm dificuldades de vender mercadorias.

Tecendo um conjunto de considerações sobre o movimento contraditório do capital, Tumolo assinala que:

“no capitalismo, a construção do gênero humano (...) se dá pela sua destruição, sua emancipação se efetiva pela sua degradação, sua liberdade ocorre pela sua escravidão, a produção de sua vida se realiza pela produção de sua morte. Na forma social do capital, a construção do ser humano (...) se processa pela sua niilização, a afirmação de sua condição de sujeito se realiza pela negação desta mesma condição, sua hominização se produz pela produção de sua reificação. No limite, trata-se da constituição do fetiche do capital - o capital que se subjetiviza ou se hominiza reificando as relações sociais e o ser social"' (Tumolo, P. S., 2002, p. 16, grifos do autor).

Em consonância com este pensamento, ao analisar a sociedade capitalista, Teixeira (1995) afirma que a unidade de ligação entre produção, distri- 
buição, circulação e consumo nessa sociedade se constitui pelo mercado, e é através dele, portanto, que se tece a integração social e gesta-se a unidade do todo social. Por isso, a produção e distribuição da riqueza social passam por um processo de 'coisificação' e não obedecem mais a uma orientação consciente dos produtores, como acontecia nas formas de produção anteriores, nas quais a produção era orientada de acordo com as necessidades previamente determinadas pela comunidade. Citando Engels, Teixeira complementa sua análise afirmando que:

“todos os vínculos morais da sociedade são destruídos pela transformação dos valores humanos em valores de troca; todos os princípios éticos são destruídos pelos princípios da concorrência e todas as leis existentes (...) são suplantadas pelas leis da oferta e da demanda. A humanidade mesma se converte em uma mercadoria" (Engels apud Teixeira, 1995, p. 58).

A análise desenvolvida anteriormente permite dar um salto qualitativo na compreensão da vivência dos indivíduos que foram objeto desta investigação. Em uma primeira abordagem, tal vivência poderia ser entendida como fruto do desemprego. Contudo, o aprofundamento da análise permite compreender que o desemprego é um produto histórico de uma sociedade fundada no mercado, o capitalismo, que transformou praticamente tudo em mercadoria, sobretudo a força de trabalho. Estabelecendo esta conexão, é possível perceber que a vivência daqueles indivíduos é também um produto histórico, fruto da lógica do capital em seu movimento contraditório, e não de um fenômeno social isolado - o desemprego.

Os desempregados entrevistados, que representam apenas uma pequeníssima representação dos milhões, talvez bilhões de indivíduos que, ao redor do mundo, vivem nesta mesma condição, se encontram numa situação de dificuldade e, no limite, impossibilidade de vender não somente a força de trabalho, mas qualquer mercadoria, e, dessa forma, se encontram na dificuldade, e também na impossibilidade, de comprar os meios de subsistência para poderem produzir suas vidas como seres humanos. Ou seja, em uma sociedade de mercado como é o capitalismo, suas vidas como seres humanos estão, de fato, ameaçadas e, em alguns casos, até sua reprodução como animais - que exige apenas a satisfação das necessidades do 'estômago' também fica ameaçada. Daí se pode entender que as características de sua vivência - apresentadas anteriormente - são expressão, no seu cotidiano, da produção de sua degradação como seres humanos e, ao mesmo tempo, de suas tentativas de reação a este processo. Em poucas palavras, a vivência daqueles indivíduos é a manifestação aparente do "jogo de vida e morte" que os indivíduos têm de travar para poderem produzir-se como seres humanos na forma social do capital. 
Bertold Brecht, um dos maiores dramaturgos e poetas do século passado, tinha total clareza a respeito da relação entre o desemprego e a lógica do capital e, exatamente por isso, no final de seu poema dedicado ao desemprego (Brecht, 1990, p. 83) — valendo-se de um diálogo com os capitalistas aponta o segredo para superá-lo:

"Mas a questão é: nosso desemprego

Não será solucionado

Enquanto os senhores não

Ficarem desempregados!"

\section{Notas}

1 Professora da Universidade Estadual de Santa Catarina (Udesc). Mestre em Psicologia pela Universidade Federal de Santa Catarina.<tumolo@ced.ufsc.br>

2 Professor do Centro de Ciências da Educação e do Programa de Pós-Graduação em Educação da Universidade Federal de Santa Catarina (Ufsc). Doutor em Educação pela Pontifícia Universidade Católica (PUC-SP).<tumolo@ced.ufsc.br>

3 No final de 2002, o IBGE reformulou sua metodologia de levantamento da taxa de desemprego, alterando alguns critérios - o principal deles foi o aumento da data de referência para se considerar uma pessoa desocupada, de 7 para 30 dias — cujo resultado foi um incremento na taxa de desemprego. Para se ter uma idéia, pela nova metodologia, a taxa média de desemprego de 2002 ficou em 11,7\%, enquanto pelos critérios anteriores seria em torno de $7 \%$ (Folha de S. Paulo, 2003b, p. B-6).

4 Além dos já citados, outros investigadores, em várias partes do mundo, vêm pesquisando o referido tema. Ver, p. ex.: Garrido (1996); Catalano, Hansen e Harting (1999); Preti e Miotto (1999); Wadsworth, Montgomery e Bartley (1999); Domenighetti, D' Avanzo e Bisig (2000); Dejours (2000); Baró (1998); Silva (2000); Kilimnk (1998); Barbara (1999); Caldas (1999).

5 A pesquisa foi realizada no Sine, instituição que desenvolve um sistema de captação de vagas para o emprego nas organizações de trabalho, assim como também sua contrapartida, isto é, o cadastramento e encaminhamento dos trabalhadores que buscam inserção no mercado de trabalho. A instituição foi escolhida justamente por receber um grande número diário de trabalhadores que estão à procura de emprego.

6 Foram feitas entrevistas semi-estruturadas, uma vez que se tratava do instrumento mais adequado para a finalidade que pretendíamos atingir, tendo sido realizadas em uma das salas de reuniões do Sine, com adequadas condições para a manutenção do sigilo necessário. 
7 Os participantes foram todos escolhidos de forma aleatória dentre aquelas pessoas que estavam desempregadas e que recorreram ao Sine com o objetivo de buscar vagas para um emprego. Foram abordados, individualmente, os possíveis entrevistados para checar a disponibilidade de participação na pesquisa, no momento em que já haviam terminado de preencher o cadastro para vagas de emprego. Tal forma de abordagem se justifica pois não interferiria no momento do cadastro e, portanto, evitando qualquer prejuízo para o participante ou a instituição. Dos indivíduos abordados e que concordaram em dar entrevistas, 13 foram realizadas, uma vez que as informações, interpretações e sentimentos das pessoas começaram a repetir-se. Todas as entrevistas foram transcritas pelos próprios pesquisadores. A escuta e transcrição de todas as entrevistas foram realizadas várias vezes, com o objetivo de tornar a transcrição o mais fidedigna possível e de perceber e interpretar os sentimentos, manifestos em pausas, choro, alteração de tom e volume da voz. Depois se compararam os dados apresentados na revisão bibliográfica e os resultados encontrados a partir dos relatos dos participantes desta pesquisa.

8 A tabela demonstra que o maior número de desempregados $(5-38,46 \%)$ se encontra na faixa de 30 a 34 anos.

9 Vide lista dos pesquisadores na nota n. 4.

10 A respeito da análise que alguns autores, inclusive no campo da psicologia, fazem sobre o desemprego no interior do sistema capitalista, bem como de seus limites, vide, entre outros, Tumolo, L. M. S. (2002).

11 Como o leitor poderá observar, a análise desenvolvida a partir daqui está baseada no referencial teórico marxiano acerca da crítica da economia política, sobretudo em $\mathrm{O}$ capital (Marx, 1983, 1984).

12 Cremos que seria preciso salientar que as razões pelas quais a produção na forma especificamente capitalista é muito mais propícia ao aumento da força produtiva do trabalho - e, por desdobramento, à redução do valor da mercadoria - do que a produção na forma não-capitalista são de tamanha complexidade que sua explicação detalhada fugiria aos limites deste artigo.

13 Estamos nos referindo, aqui, a produtores e vendedores não-capitalistas de mercadorias. A condição dos vendedores capitalistas de mercadorias não é objeto de discussão deste texto.

14 A análise do capitalismo demanda que se faça uma diferenciação entre a força de trabalho e o trabalhador, uma vez que, nesta forma social, apenas a primeira se transforma em mercadoria, e não o trabalhador, como ocorre no escravismo. Para que a força de trabalho se converta em mercadoria, duas condições têm de ser cumpridas: 1) o trabalhador tem de ser proprietário da força de trabalho e, portanto, responsável por sua produção e reprodução; e, 2) o trabalhador precisa ser livre, no duplo sentido de que ele dispõe, como pessoa livre, da força de trabalho como sua mercadoria, e estar livre e desimpedido da propriedade de qualquer meio de produção, o que implica que está impossibilitado de produzir os meios de subsistência para a produção de sua própria vida e, portanto, de sua força de trabalho. Por outro lado, deve-se assinalar que a força de trabalho como mercadoria se diferencia de outras mercadorias porque ela tem a exclusividade de três atributos: como valor de uso nas mãos do capitalista, produz valor novo, transfere os valores antigos para a nova mercadoria produzida e, principalmente, produz mais-valia, e, por desdobramento, capital. Faz-se necessário esclarecer, ainda, que a força de trabalho só pôde surgir como merca- 
doria, assim como todas as outras mercadorias, com o advento da propriedade privada, o que quer dizer que se trata de uma construção histórica. Embora não seja, como mercadoria, exclusiva do capitalismo, se torna nele a mercadoria determinante, já que, na relação especificamente capitalista, é a única fonte de produção de mais-valia e de capital.

15 Um exame detalhado e aprofundado a respeito desse processo contraditório pode ser encontrado em O Capital, de Marx (1984), especialmente no capítulo XXIII, denominado 'A lei geral da acumulação de capital'.

16 Para um aprofundamento da questão do desemprego no interior da lógica societal do capital, vide, entre outros, Moretto (2004).

\section{Referências}

ANTUNES, Ricardo. 1999. Os sentidos do trabalho. São Paulo: Boitempo.

BARBARA, Maristela. 1999. Reestruturação produtiva, qualificação, requalificação e desemprego: percepção e sofrimento do trabalhador. Psicologia Ciência e Profissão, n. 1, p. 30-49.

BARÓ, Ignácio. 1998. La liberación como horizonte de la psicología: psicologia de la liberación. Madri: Editorial Trolta.

BOCK, Ana. 1999. O lugar do trabalho na psicologia social. Mesa redonda da Associação Brasileira de Psicologia Social. São Paulo.

BRASILEIRO, Maria. 2000. O significado da perda do emprego para trabalhadores desempregados. Relatório final de pesquisa (Programa Institucional de Bolsa de Iniciação Científica-PIBIC/CNPq). Departamento de Psicologia, Universidade Estadual da Paraíba.

BRECHT, Bertolt. 1990. Poemas. 1913-1956. 4. ed. São Paulo: Brasiliense
CALDAS, Miguel. 1999. A demissão e alguns significados psicológicos da perda do emprego para o indivíduo. In: Enanpad (Encontro Nacional de Pós Graduação e Pesquisa em Administração). Anais. CDROM, Rio de Janeiro.

CATALANO, Ralph; HANSEN, Hans; HARTING, Terry. 1999. The ecological effect of unemployment of very low birthweight in Norway and Sweden. Journal of Health and Social Behavior, v. 40, p. 422-428.

CATTANI, Antônio. 1996. Trabalho e autonomia. 12. ed. Petrópolis, RJ: Vozes.

DEJOURS, Christophe. 2000. A banalização da injustiça social. 3. ed. Rio de Janeiro: Fundação Getúlio Vargas.

DIEESE. 1999. Reestruturação tecnológica e emprego no comércio em Santa Catarina. Estudo Regional 3. Florianópolis: Dieese. DOMENIGHETTI, Gianfrancesco; DÁVANZO, Barbara; BISIG, Brigitte. 2000. Health effects of job insecurity among employ- 
ees in the Swiss general population in international. Journal of Health Services, v. 30, n. 3, p. 477-490.

FOLHA DE S. PAULO. 2003a. Desemprego cai, mas motivo é desalento. Folha de $S$. Paulo, São Paulo, 25 jan. Caderno B, p. 6.

FOLHA DE S. PAULO. 2003b. Para IBGE, manter duas taxas é 'infundado'. Folha de S. Paulo, São Paulo, 25 jan. Caderno B, p. 6.

FORRESTER, Viviane. 1997. O horror econômico. São Paulo: Unesp.

GARRIDO, Alicia. 1996. Psicologia social del desempleo. In: ALVARO, José L.; GARRIDO, Alicia; TORREGROSA, José Ramon. (Orgs.). Psicologia social aplicada. Madrid: McGraw-Hill/Interamericana de Espana, p. 121-154.

KILIMNIK, Zélia. 1998. Trabalhar em tempos de "fim de emprego". Psicologia, Ciência e Profissão, n. 2, p. 34-45.

LEJOYEUX, Michel; BOULENGUIEZ, Sofhie; FICHELLE, Anika. 2000. Alcohol dependence among patients admited to psychiatric emergency services. General Hospital Psychiatry, n. 22, p. 206-212.

LANE, Silvia T. M. 1995. A mediação emocional na constituição do psiquismo humano. In: LANE, Silvia T. M.; SAWAIA, Bader B. (orgs.). Novas veredas da psicologia social. São Paulo: Brasiliense.

LONDOÑO, Juan L. 1997. Pobreza, desigualdade, política social e democracia. In: LANGONI, Carlos G. (coord.). A nova América Latina. 2. ed. Rio de Janeiro: Fundação Getúlio Vargas.

MARX, Karl. 1983. O capital. v. I, tomo 1. São Paulo: Abril Cultural.

. 1984. O capital. v. I, tomo 2. São Paulo: Abril Cultural.

MATTOSO, Jorge. 2000. O Brasil desempregado. 2. ed. São Paulo: Fundação Perseu Abramo.

MORETTO, Nivaldo R. 2004. A formação sindical-profissional da Central Única dos Trabalhadores (CUT), desemprego e a configuração atual do mercado capitalista. Dissertação de Mestrado, Florianópolis: UFSC.
POCHMANN, Marcio. 1999a. O fenômeno do desemprego no Brasil: diagnóstico e perspectivas. Documento elaborado para o Crub (Conselho de Reitores das Universidades Brasileiras), setembro de 1999. 1999b. O trabalho sob fogo cruzado. São Paulo: Contexto. 2001. O desemprego na globalização. São Paulo: Boitempo.

PRETI, Antonio; MIOTTO, Paola. 1999. Suicide and unemployment in Italy. Journal Epidemiol. Community Health, n. 53, p. 694-701.

SEVE, Lucien. s.d. Marxismo e a teoria da personalidade. Lisboa: Livros Horizonte.

SILVA, Seligman. 2000. Saúde Mental e Trabalho. In: TUNDIS, Silvério; COSTA, Nilson (orgs.). Cidadania e loucura. Petrópolis, RJ: Vozes, p. 266-273.

TEIXEIRA. José. 1995. Pensando com Marx. São Paulo: Ensaio.

TUMOLO, Ligia M. S. 2002. As características da vivência das pessoas que se encontram desempregadas em Florianópolis $S C$. Dissertação de Mestrado, Florianópolis: Universidade Federal de Santa Catarina.

TUMOLO, Paulo S. 2002. O significado do trabalho no capitalismo e o trabalho como princípio educativo: ensaio de análise crítica. In: 24a Reunião da Anped, Caxambu. p. 1-21. CD ROM, Caxambu: Associação Nacional de Pós-Graduação e Pesquisa em Educação.

.2003. Trabalho, vida social e capital na virada do milênio: apontamentos de interpretação. Educação \& Sociedade, v. 24, n. 82, p. 159-178.

WADSWORTH, M.; MONTEGOMERY, S.; BARTLEY, M. 1999. The persisting effect of unemployment on health and social well-being in men early in working life. Social Science and Medicine, n. 48, p. 1491-1499.

Recebido em 01/05/2004

Aprovado em 03/08/2004 